\title{
Clearing the Path on the Endless Frontier
}

\section{Kim A. Wilcox, Chancellor, University of California, Riverside}

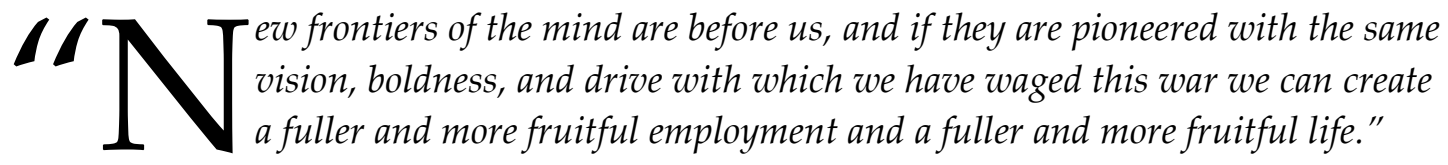

--Franklin D. Roosevelt

Letter to Vannevar Bush

November 17, 1944

As World War II neared its end, President Franklin Roosevelt wrote to Dr. Vannevar Bush, head of the Office of Scientific Research and Development and former dean of the MIT School of Engineering. President Roosevelt tasked him with formulating a strategy for postwar federal support of scientific research that built on the successes seen during wartime. With the help of four committees of scientists and scholars, Dr. Bush produced the seminal Science: The Endless Frontier.

Recognizing the need for a formal national strategy of scientific research, Dr. Bush and his collaborators laid out a plan for a federal agency focused on promoting research. Five years later, his proposal was partially realized in the creation of the National Science Foundation. The principles outlined by Bush in 1945 have guided federal support of basic research ever since.

Among his recommendations, were three core principles:

- the federal government should fund basic research through the nation's universities;

- free inquiry is essential to the creation of new knowledge;

- access to higher education should be based on ability, not circumstance.

In order to build research infrastructure and plan for future needs, it is essential that these three core pillars be integral to the U.S. research enterprise. While the first two principles have largely defined the U.S. research enterprise, with notable exceptions, there is still considerable work to be done in broadening access to higher education, particular at the graduate level.

\section{Introduction}

Dr. Bush's insights into building a national research strategy were borne from a career as an academician, scientist, and administrator. Recognized for his engineering work in data retrieval that presaged modern computing, he was most noted for his role in guiding the U.S. research enterprise that was vital in World War II. After six years as dean at MIT, Bush was named as director of the prestigious Carnegie Institution of Washington, a major funder of research nationally. Once in Washington, D.C., he approached the White House about improving the nation's scientific research. In 1940, he proposed and was named chairman of the National Defense Research Committee (NDRC), charged with coordinating wartime research. In 1942, he 
was named director of the newly formed Office of Scientific Research and Development (OSRD) where he shepherded the creation of radar and facilitated creation of the Manhattan Project (the "Uranium Committee" had been under his supervision at both NDRC and OSRD), among other projects. In plaudits not usually reserved for Washington bureaucrats, Bush received considerable notoriety for his role during the war. A 1942 article on Collier's magazine called him, "the man who may win the war," and he appeared on the cover of Time magazine in 1944 under the headline, "The General of Physics."1

Prompted by Vice President Henry Wallace, a friend and neighbor of Bush, President Roosevelt asked Bush for a formal strategy on applying the lessons of wartime research to postwar federal support of science. Science: The Endless Frontier laid out the framework for the modern research enterprise with focus on federal support of basic research conducted by universities. This vision was partially realized in 1950 with the passing of the National Science Foundation Act of 1950, which created NSF. Science: The Endless Frontier has proven to be an immensely prescient document that could not have foreseen but still managed to facilitate the world-changing scientific and technological developments that have defined the last 70 years. The broad use of nuclear energy, the space race and the invention of the Internet all point to the framework of research support ideated by Bush and his collaborators. ${ }^{2}$ He noted at the time of writing the lack of a formal body charged with developing national science policy as well as the absence of standing committees in Congress charged with this task. In addition to formulating a national research strategy, Bush's work was instrumental in putting the concept of "basic research" into the national consciousness. An analysis by Roger Pielke Jr at the University of Colorado, Boulder, documented the number of times the phrase "basic research" appeared in The New York Times, Science and Nature over the course of the twentieth century. ${ }^{3}$ Prior to publication of the report, the term was almost nonexistent, even in the scientific journals, but within 13 years of the report's publication, mentions in The New York Times alone had gone from 4 in 1944 to 159 in 1957.

\section{Federal support of university re- search}

"The publicly and privately supported colleges, universities, and research institutes are the centers of basic research. They are the wellsprings of knowledge and understanding. As long as they are vigorous and healthy and their scientists are free to pursue the truth wherever it may lead, there will be a flow of new scientific knowledge to those who can apply it to practical problems..." Science: The Endless Frontier, p. 12

Federal funding of research universities is the bedrock of basic research in the U.S. Having managed massive government-funded research enterprises, Bush recognized that only the federal government could martial the necessary resources to adequately support research efforts that would result in major discoveries and innovations. Likewise, as a former university administrator, Bush understood that universities were uniquely qualified to perform basic research.

While government and industry are more focused on applied science, Bush argued that universities, along with a 
few research institutes, were the entities most devoted to "expanding the frontiers of knowledge." Figures 1 and 2 demonstrate how funding and research patterns have closely followed Bush's conclusion. Since 1953, the federal gov- ernment has provided over 50 percent of the nation's expenditures on basic research, with some year's surpassing 70 percent. Likewise, the majority of that funding is going to universities, hovering above 50 percent in recent years (Figure 2).

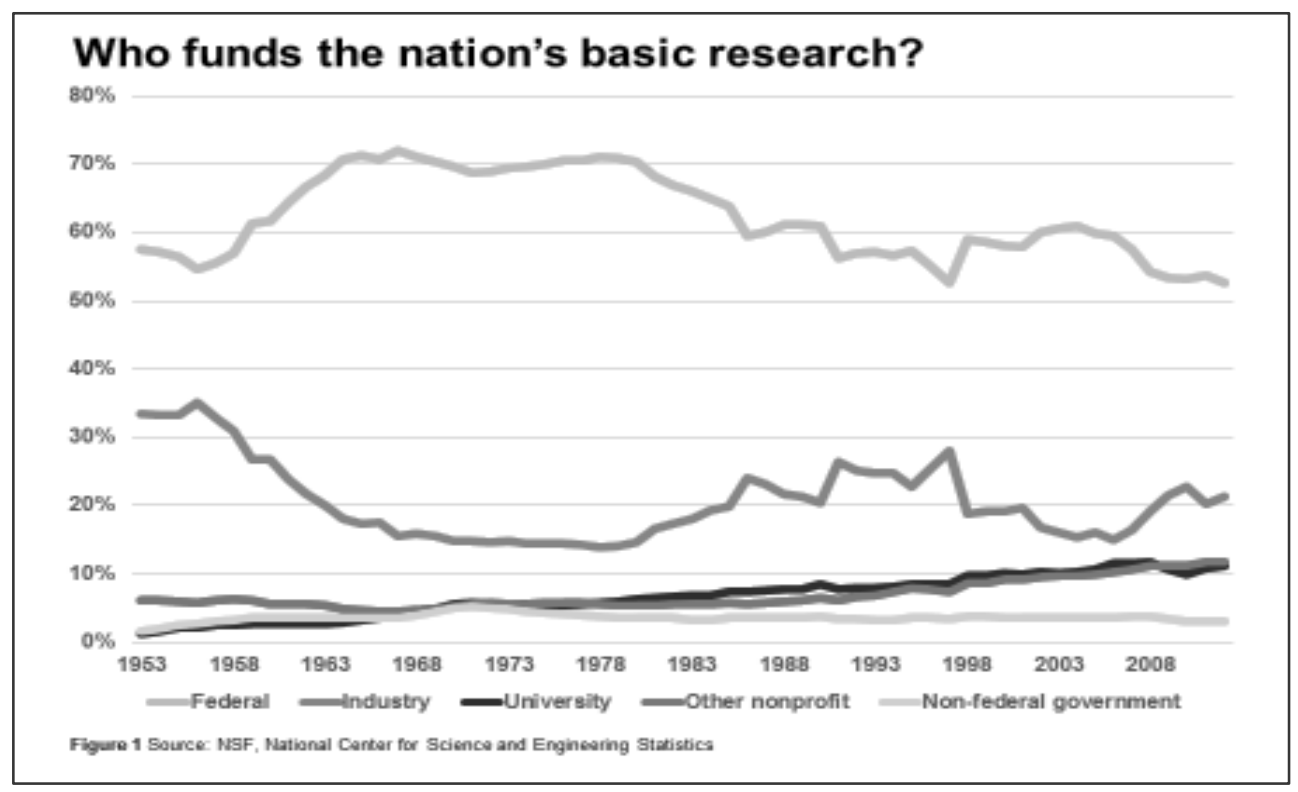

\section{Who performs the nation's basic research?}

$70 \%$

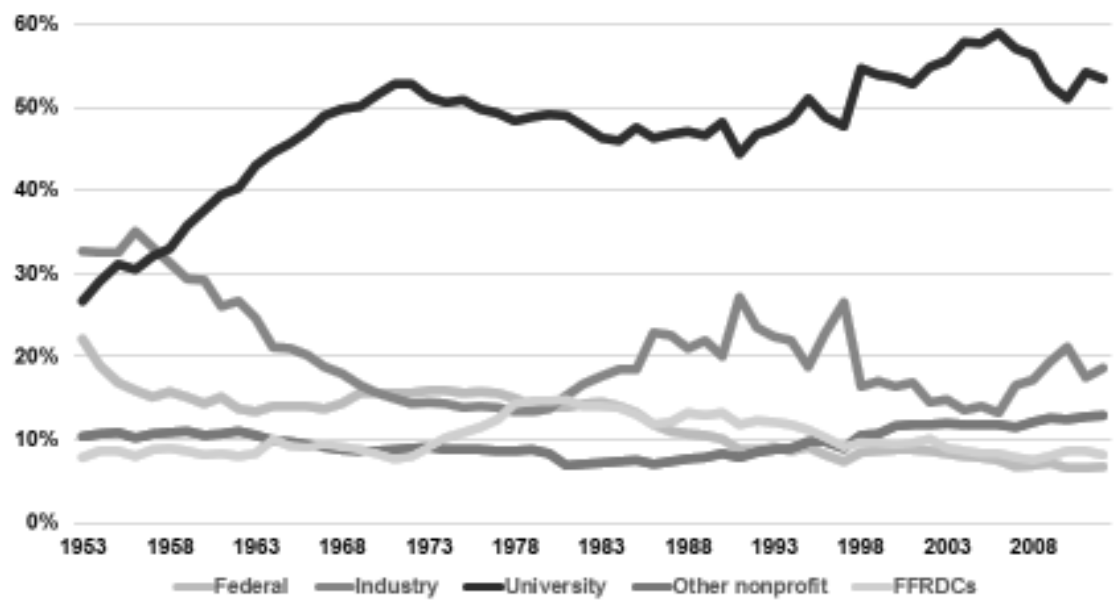

Figure 2 Source: NSF, National Cantar for Science and Enginearing Statistica 
Generally speaking, federal support of basic research enjoys broad support among the American public. In a Pew Research Center study released in 2016, 71 percent of respondents agreed that government investment in basic science research pays off in the long run. ${ }^{4}$ This public perception is reflected in the generally steady federal funding of basic research. Figure 3 delineates the percentage of U.S. federal discretionary spending dedicated to research and development since 1962. Except for significant increases in the mid-1960s, federal support of research and development has varied between 4 and 6 percent of discretionary spending. Figure 4 represents spending in FY 2016 dollars on research and development since 1953. While the overall trend of the last 60 years is positive, the recent decline followed by stagnated funding stands as a real challenge for the nation's research universities. The automatic funding cuts included as part of the 2013 budget sequestration were particularly deleterious to U.S. research efforts. The Chronicle of Higher Education surveyed 11,000 NIH and NSF grant principal investigators in 2014 about the effects of sequestration. Nearly half had abandoned an area of investigation they considered critical to their lab's mission and more than threequarters fired or failed to hire grad students and research fellows. ${ }^{5}$ Inconsistent funding as seen in the last few years not only affects the research itself but also narrows the pipeline for early career investigators who represent the next generation of researchers.

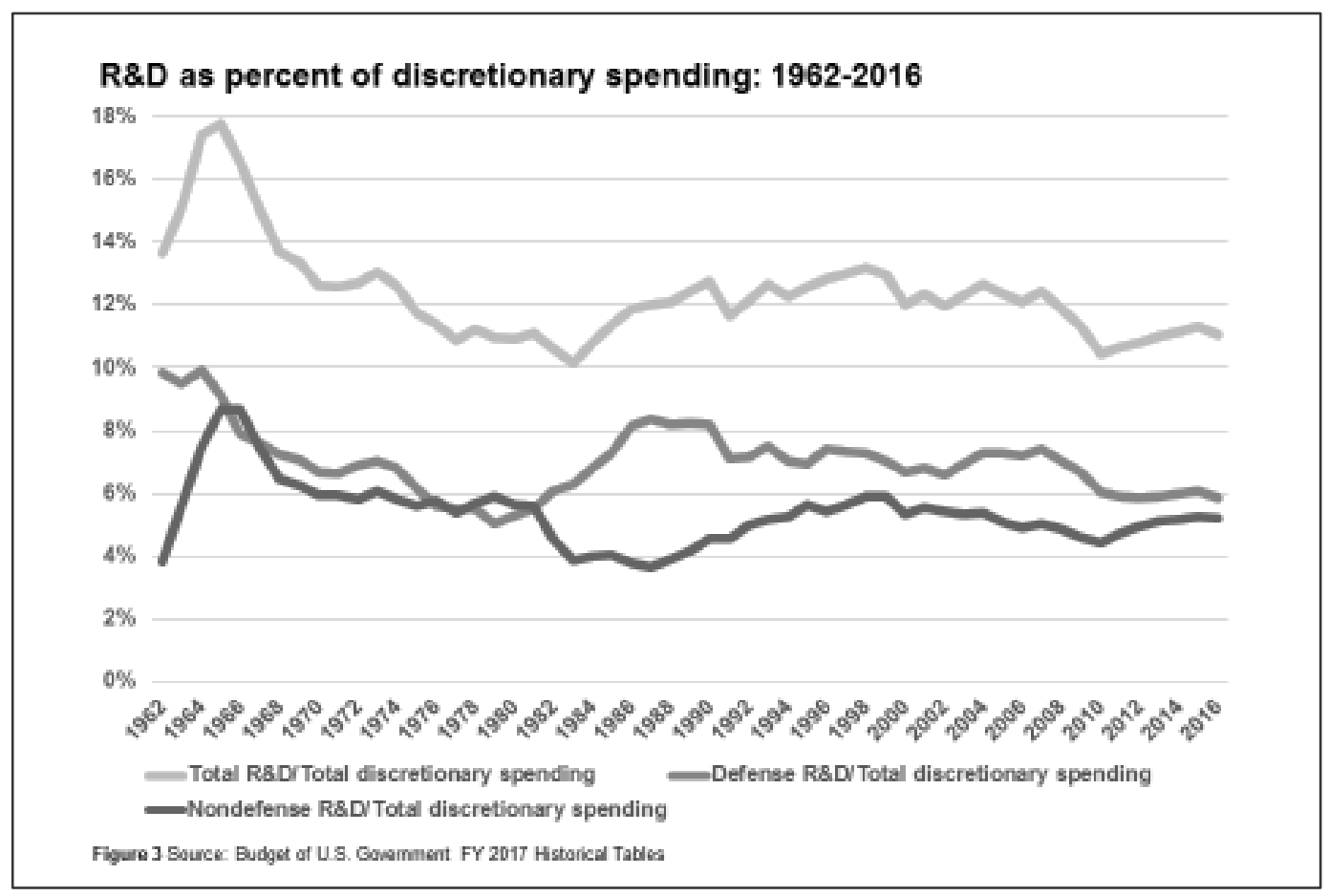




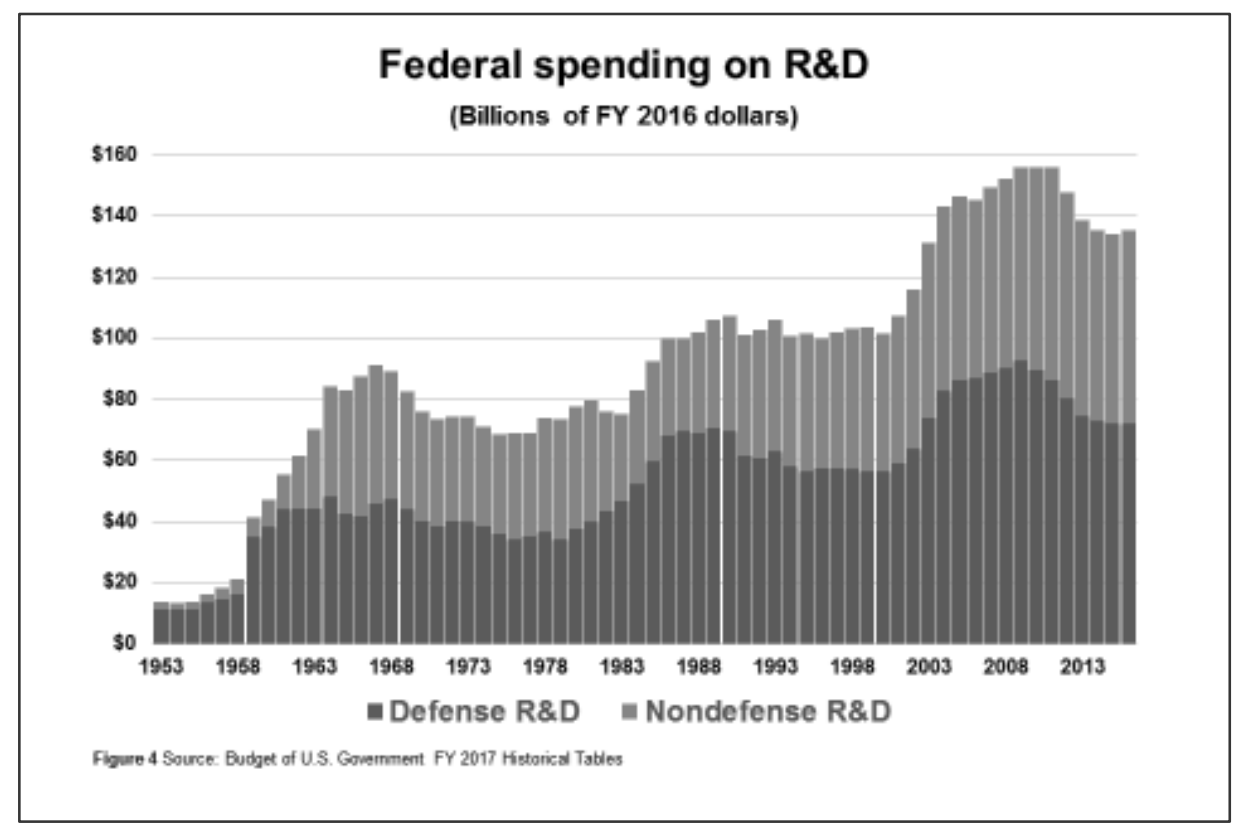

\section{II: Free Inquiry}

"Scientific Progress on a broad front results from the free play of free intellects working on subjects of their own choice, in the manner dictated by their curiosity for exploration of the unknown. Freedom of inquiry must be preserved under any plan of Government support..."

Science: The Endless Frontier, p. 12

Fundamental to Bush's argument is the conclusion that freedom of inquiry is essential to expand the frontiers of scientific knowledge. The "free play of free intellects," as he termed it, had to be preserved under any plan for government support of science. His report was published at the end of World War II when selling the idea of "basic research" to both public and politicians was relatively easy considering the immediate evidence of seemingly arcane scientific discovery leading to development of the atom bomb, radar and penicillin. The peer review process has been critical in balancing the need to be accountable with taxpayer funds while also allowing for researchers to pursue knowledge wherever it may be found.

Unfortunately, some politicians and media have taken to disparaging the work of peer-reviewed scientists as silly and wasteful. ${ }^{6}$ These efforts are an attack on free inquiry and threaten to turn the U.S. research enterprise into an effort that can only achieve innovation on the edges of discovery, rather than realizing truly groundbreaking discovery. Much of the political ire has been directed at efforts in the social and behavioral sciences. It is important to note that behavioral and social factors are responsible for more than 50 percent of the preventable injuries, illness and deaths in the U.S. Bush also argued this point, calling it "folly" to pursue the natural sciences and medicine at the cost of the social sciences and humanities.

The freedom to pursue knowledge wherever interests lie is a foundational component of basic research. Scores of seemingly esoteric, trivial or silly sounding research projects have led to some of 


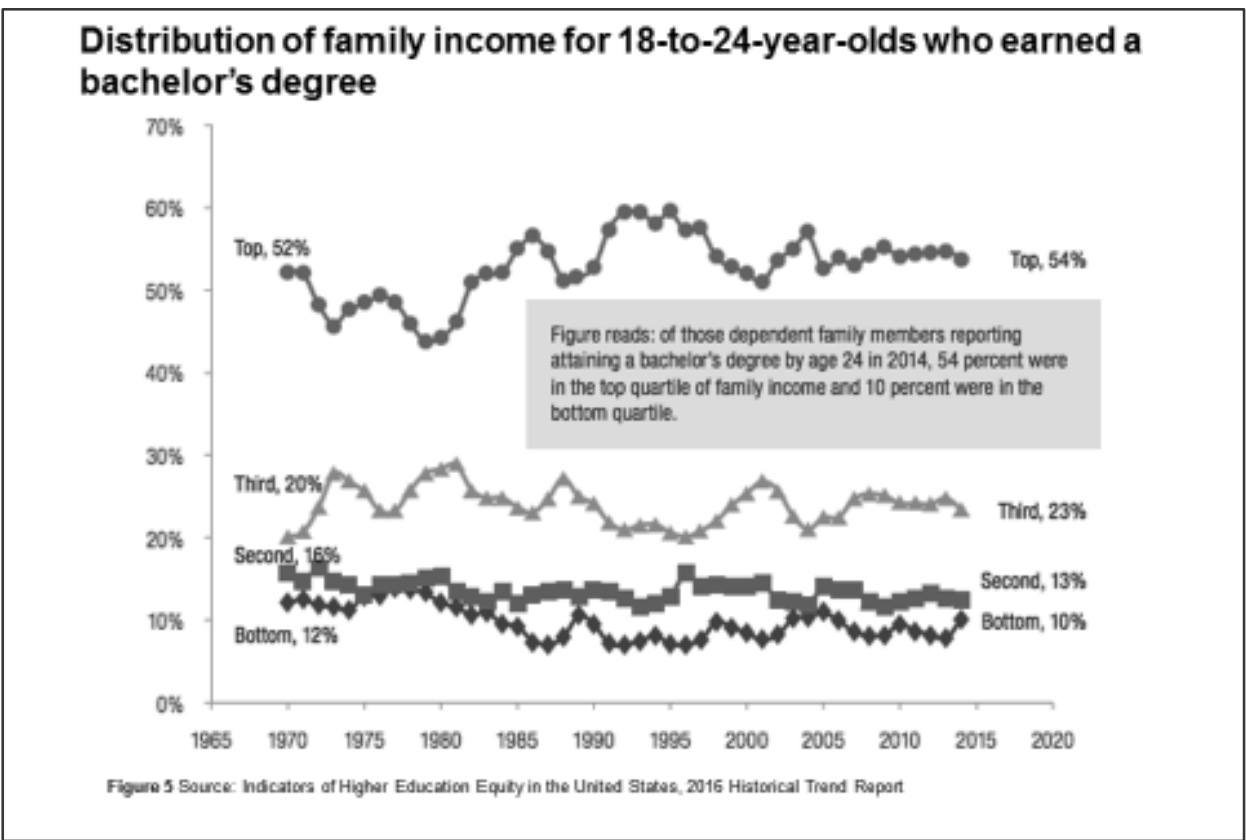

the most important scientific discoveries and innovations. Genomic studies of nematode worms have identified genes critical in new cancer and Alzheimer's treatments. GPS exists because of research in atomic physics. In 1995, two grad students at Stanford were working on the NSF-supported Digital Library Project. They were working on an early search engine that they called "BackRub." The seemingly unserious sounding BackRub became Google, the brainchild of two students, Larry Page and Sergey Brin.

\section{IV: Broadening educational oppor-} tunities

"There are talented individuals in every segment of the population, but with few exceptions those without the means of buying higher education go without it. Here is a tremendous waste of the greatest resource of a nation - the intelligence of its citizens"

Science: The Endless Frontier, p. 25

Of Bush's three core principles of a government-supported research enterprise, the third-broadening educational opportunities - is where we are most deficient. Figure 5 represents the distribution of family income among 18-to-24year-olds who earned a bachelor's degree. It is striking that more than half of all degrees go to individuals from the top quartile of family income while only 10 percent of degrees go to those from the lowest earning quartile. Clearly, these data are cause for concern on a variety of levels. The fact that family income still stands as a prime determining factor for whether someone will graduate from college holds not only a variety of social and economic consequences but also represents a headwind to our efforts to realize discovery and innovation through basic research. As Bush terms it, by not broadening access to higher education, we are wasting our "greatest resource."

A causal factor for the income disparity among college graduates is that when low-income students enroll in colleges and universities, they are far less likely to graduate compared to their more affluent peers. Figure 6 compares national six- 


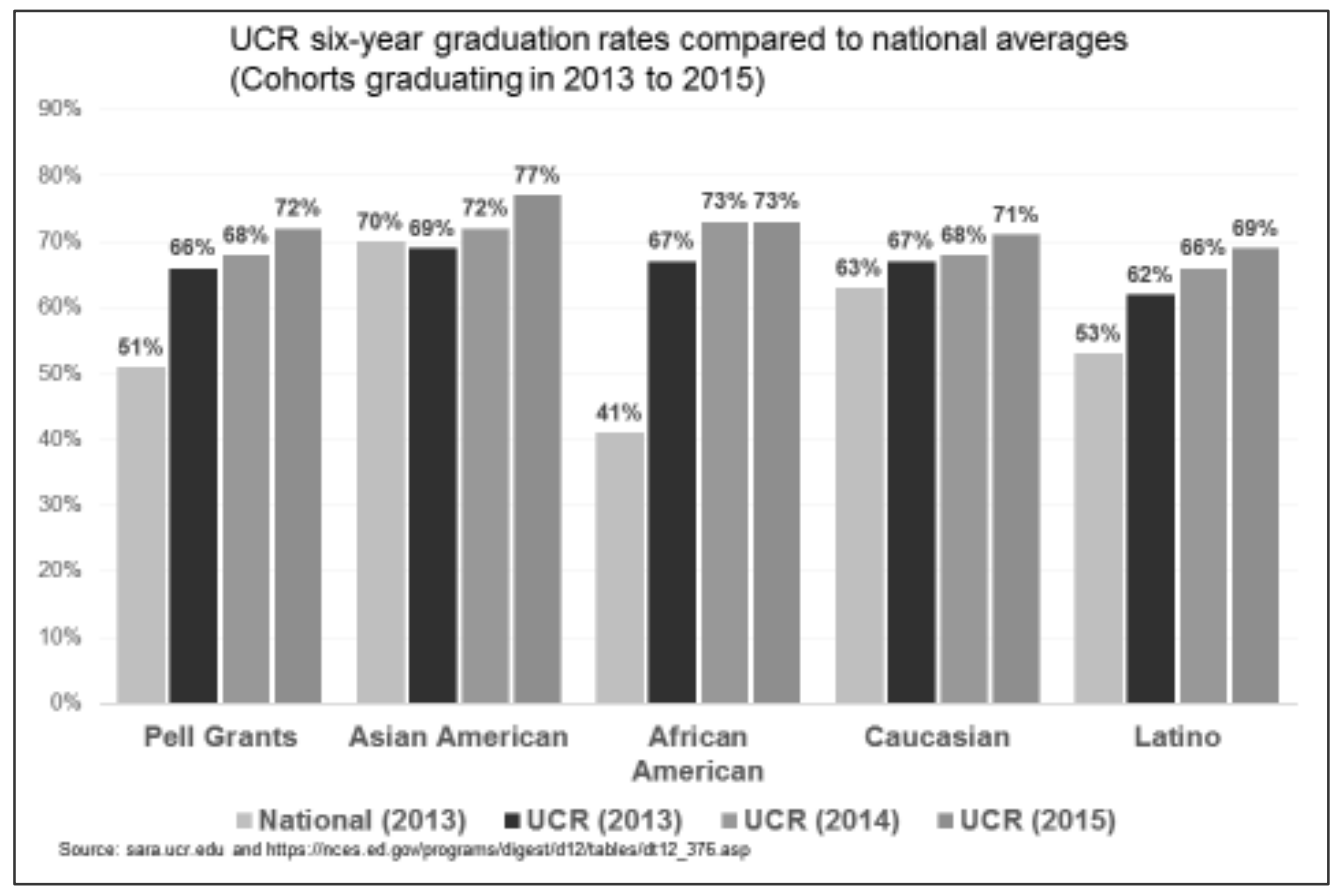

year graduation rates with the graduation rates at UC Riverside by Pell Grant status and race/ethnicity. UC Riverside is unique nationally among research institutions in that there aren't any graduation rate gaps across income and race/ethnicity categories. Likewise, UC Riverside has raised graduation rates campus-wide by 10 percent over the last three years.

Due to our record of student success, UC Riverside stands as a national model and a number of our efforts warrant mentioning here.

- First of all, you can't improve outcomes of low-income and underrepresented minority students (URM) without enrolling them first. In the mid-1990s, UC Riverside made a commitment to become the most diverse, highachieving research university in the country. That goal defines our university today. Based on our Fall 2015 enrollment data, 56 per- cent of our undergraduate students are Pell Grant recipients and 86 percent of our domestic undergraduate population are students of color.

- We have roughly 75 programs that cover the full gamut of student success, from student retention to career development. We closely monitor the progress and success of each program and a committee meets regularly to discuss gaps in programming and facilitate evaluation.

- Learning communities gather small groups of students into formal cohorts who take many of the same classes and receive focused academic support. Since initiating the learning communities, we've seen retention rates grow by 6 to 8 percent annually, with particular success among low-income and first generation students. 
Approximately two-thirds of our incoming first-year students participate in learning communities.

- Facilitating undergraduate research has been a boon to student success. More than 50 percent of our students report having engaged in faculty-mentored research during their time at UC Riverside. Our undergraduate research efforts have also proven to increase interest in pursuing graduate studies.

UC Riverside is also a founding member of the University Innovation Alliance (UIA). Founded in 2014, UIA is a consortium of 11 large public research universities committed to improving outcomes among low-income and minority students. UIA is also supported by five foundations, including the Bill \& Melinda Gates and Ford foundations. We are identifying and piloting new innovations to improve student success and also scaling proven innovations that improve graduation rates. The UIA collaborative initiatives include:

- Predictive analytics and datadriven interventions

- Computer-based adaptive learning to tailor to students' needs

- Financial interventions such as financial literacy education and "just-in-time" grants

- Pre-college bridge programs that reach out to students as early as middle school

- Targeted student support that uses data to provide specific support to student subgroups

\section{V: Conclusion}

The Government should accept new responsibilities for promoting the flow of new scientific knowledge and the development of scientific talent in our youth. These responsibilities are the proper concern of Government, for they vitally affect our health, our jobs, and our national security.

Science: The Endless Frontier, p. 8

The vision for government-led research laid out by Vannevar Bush over 70 years ago still guides our efforts to realize discovery and achieve innovation, but considerable work still remains to reach the full potential envisioned by Bush. Out of the three core principles outlined by Bush for a successful program - federal support of university-based researchers, free inquiry, and expanded educational opportunities-we remain woefully inadequate on the third. As long as six-year graduation rates of Pell Grant recipients remain close to 50 percent and as long as only half of Latino/Hispanic students and less than half of African American students graduate in six years, we will continue to fall short of our potential in fostering research discoveries. And these figures only account for those students who make it to college in the first place. Additionally, income continues to stubbornly dictate to a large degree who succeeds at the college-level. While many institutions have proven capable of defying these trends, we need to replicate these successes on a massively larger scale not only to realize the much larger societal benefits but also bolster the research enterprise that has proven so beneficial to our nation and the world. 


\section{References}

1. Dizikes, P. (2011). "A difference maker." MIT News.

http://news.mit.edu/2011/time$\underline{\text { line-bush-0216 }}$

2. Waterman, A. (1960). Introduction to Science: The Endless Frontier. Reprinted by the National Science Foundation.

3. Pielke, R. (2010). In Retrospect: Science-The Endless Frontier. Nature. Vol 466. August 2010.

4. American Institute of Physics (2015). Survey Finds Broad Public Support forFederal Basic Research Fund-

ing.https://www.aip.org/fyi/2015/ survey-finds-broad-public-support-federal-basic-research-funding

5. Massachusetts Institute of Technology (2015). The Future Postponed: Why Declining Investment in Basic Research Threatens a U.S. Innovation Deficit.

6. Office of Senator Jeff Flake (2015). Wastebook: The Farce Awakens. http://www.flake.senate.gov/public/ cache/files/03714fa3-e01d46a1-9c19-299533056741/wastebook---the-farce-awakens.pdf 